\title{
Student-Generated Podcasts for Learning and Assessment
}

\author{
Colin G. Johnson \\ Computing Laboratory \\ University of Kent \\ Canterbury, Kent, CT2 7NF \\ England \\ C.G.Johnson@kent.ac.uk
}

\begin{abstract}
The aim of this paper is to discuss our experience with, and some broader thoughts on, the use of student-produced podcasts as a means of supporting and assessing learning. The results of an assessment using this medium are reported, and student evaluation of the assessment presented and discussed.
\end{abstract}

\section{INTRODUCTION}

The aim of this paper is to discuss our experiences with using student-produced podcasts as a means of assessment in computer science.

Podcasts, and related media such as radio programmes, are an increasingly important way of communicating science to a general audience. Using podcasts as an assessment method presents an opportunity for students to engage with course material in a fresh new medium.

A number of projects have tackled aspects of university learning using podcasts. Most commonly, these are used as ways of presenting course material. For example, the ProfCast software (www.prof cast.com) is widely used in many universities to record and make available lecture material. A large amount of advocacy has been made concerning this teaching style. However, only a small number of studies (e.g. $[12,8,9]$ ) have attempted to evaluate the effects on learning. Some of the more substantial studies include those of Evans[7], Bell et al. [2], Edirsingha\&Salmon [6], and Baird\&Fisher [1]. These generally portray a positive picture of such use. However, these studies tend to show this solely from the point of view of students' self-evaluation, which is valuable but provides only a single perspective.

Another way in which podcasts have been used is in providing short podcasts that give supplementary material to students; such attempts have been analysed by Clark, Taylor et al. $[4,5]$, who give a largely positive summary of the benefits. A second use of short podcasts is in providing assessment feedback [11]. Bennedsen and Caspersen [3] have used video podcasts of the program development process to act as a demonstration of practical skill.

However, most efforts in using podcasting in education have been teacher-created. In this paper we explore the idea of student-created podcasts for learning and assessment. This has received little attention in the research

Permission to make digital or hard copies of all or part of this work for personal or classroom use is granted without fee provided that copies are not made or distributed for profit or commercial advantage and that copies bear this notice and the full citation on the first page. To copy otherwise, to republish, to post on servers or to redistribute to lists, requires prior specific permission and/or a fee.

Koli Calling '08 November 13-16, 2008, Koli, Finland

Copyright 2008 ACM 978-1-60558-385-3/08/11 ...\$5.00. literature. One recent example is given by Thompson [13], who discusses the use of student-created podcasts as a way for teacher-training students to reflect on their learning and to provide a repertory of teaching tips to be shared amongst students on a course.

\section{THE ASSESSMENT}

We prepared a podcast-based assessment as a component ( $5 \%$ of total module marks) of the assessment on our Introduction to Intelligent Systems module. This is typically taken by students mid-way through their degree, and is typically taken by $40-50$ students. There were a number of reasons for adopting this form of assessment:

- We hypothesised that students would find an alternative form of assessment interesting and fresh, and would engage student interest more than an assessment in a previously encountered style. In particular, we believed that students at this stage in their degree might be revitalised by being presented with a novel form of assessment.

- We wanted students to begin to engage with the research literature. However, at their stage of subject knowledge, asking detailed questions requiring technical knowledge of research literature is too advanced. Therefore, this was seen as a way of getting students to engage with the gist of some research papers, without having to go into technical detail. Therefore, this assessment acts as part of the students' learning on the course, as well as forming a summative assessment.

- We believe that it is an important skill for science students to be able to communicate about their work to a general audience, and this type of activity provides some early practice in this.

The assessment is given in figure 1. Students could work on this as individuals or in a group of two (in which case both students get the same mark). Students were also given advice about how to cite sources, and how to hand in the assessment. Beyond the advice given in the assessment, no specific guidance was given about the practical issues of creating the podcast; it was assumed that students doing a computing degree would have sufficient general IT knowledge to be able to work this out for themselves (students with practical issues were encouraged to contact the course tutor; no such queries were raised). If this kind of assessment were to be applied elsewhere, it would be probably be necessary to provide more detailed instructions/training in the use of recording software and equipment. 


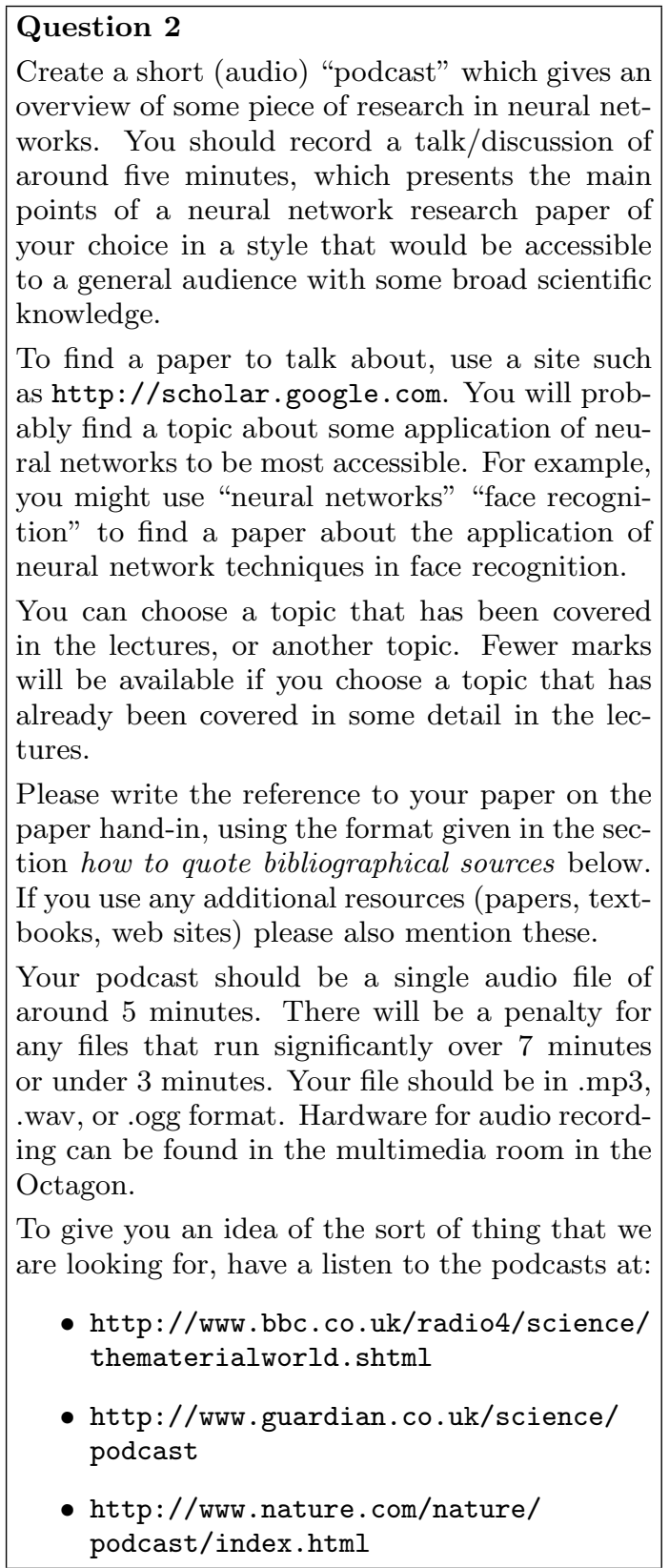

Figure 1: Details of the podcast assessment.

\section{ISSUES FROM THE ASSESSMENT}

A number of issues arose from the assessment and from thinking around this kind of assessment in general.

\subsection{Student Reaction}

The first reaction we received to setting this assessment was a student asserting that the form of the assessment was "offensive" and "degrading". A couple of students also sought reassurances that the audio files would not be made available on the department website or to other students. The nub of this seems to be that the use of voice, as opposed to written material, has a "personal" quality to it, that is not an issue when it comes to other forms of presentation. In particular, the recorded voice has particular issues, as we are not accustomed to the sound of our recorded voice, and many people react negatively to hearing their recorded voice.

Other students informally expressed a positive attitude towards the assessment, in particular commenting on it being something interestingly different to what they usually do.

\subsection{Unexpected Issues}

A small number of unexpected issues arose as a result of the assessment:

Two students chose to submit work using a computersynthesized voice, one explaining that they had attempted to record their voice and had not liked it, another submitting in this form without explanation.

One student "group" consisted of two students, but only one spoke on the recording.

Several students complained about the difficulty in finding relevant research papers, in particular ones that were available without charge, despite the advice given about finding papers. This was surprising, but might reflect (1) students working off-campus and not having automatic IP-related logins to certain university library subscription journals, or (2) weak web-search skills on behalf of the students.

\subsection{Diversity Issues-Disability and Person- ality Diversity}

This form of assessment could provide particular difficulties for students with certain disabilities, which do not occur as problems elsewhere in the range of assessments. We offered an alternative assessment to any students who were affected by this.

Another diversity related issue relates to the well-known idea that a wide range of assessment methodologies is a positive thing because it gives students with different preferences in styles of learning/presentation an opportunity to shine. Does this sort of assessment, for example, give an opportunity for students who are more fluent in speaking to be assessed using those skills, as opposed to the fluency in writing that is assessed in many assessments? Or is this diversity in preferences overemphasised?

\subsection{Marking}

One of the advantages of this as an assessment medium is that marking is very practical. It is possible to listen to the assessment whilst simultaneously writing comments. This presents a valuable practical advantage to this form of assessment, as we are are under increasing pressure to find forms of assessment that can be marked efficiently without compromising on the quality of evaluation or feedback given.

One issue of concern encountered during marking was that of form versus content. We decided not to specifically allocate marks to these two aspects of the assessment, as it is in practice difficult to separate them out. Whilst informal efforts were made to avoid being swayed by the presentational confidence of the students, there is a danger in marking this kind of work that a presentation presented confidently and fluently can have a spurious authority that a better-researched but shoddily presented piece of coursework does not have.

A few students submitted files that, despite claiming to be in one of the formats specified, did not play using standard software. Sorting out these issues took a lot of time.

One useful exercise for analysing an assessment is to note what comments were made repeatedly when marking the work. This can be usefully communicated back to the students for general feedback, and to future years of students as "common pitfalls". When marking this work, the following issues came up in a number of different stu- 


\begin{tabular}{|c|c|c|c|c|c|c|c|}
\hline Question & 1 & 2 & 3 & 4 & 5 & Mean & StdDev \\
\hline $\begin{array}{l}\text { Did you think that this was a useful assessment in terms of learning } \\
\text { new material and presenting what you had learned? ( } 1 \text { (not useful) }-5 \\
\text { (very useful)) }\end{array}$ & 2 & 1 & 3 & 4 & 3 & 3.4 & 1.3 \\
\hline $\begin{array}{l}\text { Do you think that this is a kind of assessment that we should use in } \\
\text { the future? ( } 1 \text { (not at all)-5 (yes, very much)) }\end{array}$ & 3 & 2 & 2 & 4 & 2 & 3.0 & 1.4 \\
\hline $\begin{array}{l}\text { Was the assessment well explained? ( } 1 \text { (not at all well explained) }-5 \\
\text { (very well explained)) }\end{array}$ & 0 & 2 & 5 & 3 & 3 & 3.5 & 1.0 \\
\hline
\end{tabular}

Table 1: Numerical evaluation of the assessment: question, numbers of responses at each scale-point 1-5, mean, standard deviation.

dents' work:

- There is not enough structure to the talk; alternatively, there is structure, but the "scaffolding" language used to flag up the structure was not present.

- There were inconsistencies in the granularity of explanation throughout the talk. In particular, students would leap from highly detailed explanations of one component of the material, to very general explanations of a related part. Also, some weak assessments didn't show any sense of direction to the granularity: they might have been improved e.g. by starting with higher level explanations and then "drilling down" to more technical detail.

- There were problems with the use of technical vocabulary. Some students used a vocabulary that was far too advanced for the audience specified. Instead, they could either have defined technical terms in simpler language, or sometimes just avoided it and explained things directly in a simpler way.

By contrast, the following were positive features that appeared commonly in marking

- Well structured, and structure well explained.

- Clear explanation.

- Appropriate for the specified audience.

\subsection{Evaluation}

Students were asked to evaluate the podcast assessment in two ways: through three questions on a 5-point Likert scale, and through free text comments. The results from the numerical evaluation are given in table 1 . Thirteen students responded. Overall these results show a very mixed view of the assessment.

The free text comments also showed a diversity of opinion about the value of the assessment. A number of students remarked positively on the originality of the method of assessment, and the ability to choose a topic freely within the scope of the module. However, a number of students expressed problems with knowing what assumptions should be made about the audience, about access to papers (as noted above) and finding relevant papers, and about the practicalities of recording and producing an effective podcast. A number of students suggested that a written alternative should have been offered, and commented on the lack of a detailed mark scheme.

\section{CHANGES}

There are a number of things that we might do differently if presenting a similar assessment in future years. In particular, we would consider:
- Give some more instructions about how to structure a presentation in this form. A number of podcasts submitted showed evidence that students had read and understood the material, but the actual presentation was weak. In particular, ways of marking out sections and providing a "scaffold" for the overall structure of the talk.

- Give more detailed instructions about how to find a relevant paper, in particular instructing the students that they might find more free-to-access papers by using a computer on the university campus rather than their computer at home.

- Providing more explicit guidance about the audience that the podcast should be targeted at; one way to do this would be to give particular exemplars of the kind of audience being targeted rather than a generic description.

- We are uncertain as to whether it would be sensible to divide the marks for form and content. Whilst this would potentially be valuable, it may prove difficult to do in practice.

\section{QUESTIONS FOR DISCUSSION}

- One argument for setting this kind of assessment is that a large proportion of students doing the assessment are "digital natives" [10], and are likely to relate to material such as podcasts rather than traditional forms of assessment such as essays. Is this really true? There does not appear to have been any academic work on the demographics of podcast listeners, and evidence from less formal surveys reported in the press appears to be inconclusive (see e.g. http://www. coms core. com/press/release. asp? press=1438,http: //www . eweek. com/c/a/Messaging -and-Collaboration/What-Blogs-Podcasts -Feeds-Mean-to-Bottom-Line/, http://www. vnunet. com/vnunet/news/2141338/ youth-today-spurn -podcasting). How much do students expect university work to reflect the values of the "world outside" versus being an internal world with its own ways of doing things?

- Is it appropriate to expect students to "perform" in this fashion? Is it beyond the reasonable expectations of students that they are assessed using the medium of recorded voice? Is this too personal a medium to be used in assessment?

- Is there a demographic bias in the kind of students who listen to podcasts, and therefore a bias in the assumption that this is a more "native" form of assessment for most students. For example, some surveys 
of podcast usage have suggested gender and age biases in general podcast listening (e.g. http://www . comscore $. \mathrm{com} / \mathrm{press} / \mathrm{release}$. asp?press=1438). Is this an issue for the use of podcasts in learning?

- How can we separate form and content in marking this kind of assessment? Indeed, should we?

- Could we use these in a shared fashion, e.g. for sharing information between students? Would there be a way of introducing this so that students would find it acceptable?

- Is there a danger of the advantages of this being temporary? Is there a danger with these "gee-whiz" technologies just being seen as a vacuous attempt to "be trendy"?

- Is this a particularly good, or particularly bad, form of assessment for computer science students by contrast with students from other subjects?

- Would it be interesting to explore a multi-episode podcast, e.g. as a way of getting students to reflect on an ongoing piece of project work?; or, as a way of supporting student learning by asking them to produce a regular podcast covering various chapters of a book, a collection of research papers, or similar.

\section{CONCLUSIONS}

We have discussed our attempt at using student-generated podcasts as a way of promoting learning and of carrying out assessment. Overall, the reaction to this amongst students was mixed. We have presented a number of issues that arose during the development and marking of this assessment, and presented a number of questions for discussion and for refection by teachers who are planning to use this form of assessment themselves.

\section{REFERENCES}

[1] Derek E. Baird and Mercedes Fisher. Neomillennial user experience design strategies: Utilizing social networking media to support "always on" learning style. Journal of Educational Techology Systems, 34:1, 2005-06.

[2] T. Bell, A. Cockburn, A. Wingkvist, and R. Green. Podcasts as a supplement in tertiary education: an experiment wih two computer science courses. In Proceedings of MoLTA 2007, 2007.

3] Jens Bennedsen and Michael E. Caspersen. Revealing the programming process. SIGCSE Bull., 37(1):186-190, 2005.

[4] Steve Clark, Catherine Sutton-Brady, Karen M. Scott, and Lucy Taylor. Short podcasts: The impact on learning and teaching. In Proceedings of mLearn 200\%, pages 285-289, 2007.

[5] Steve Clark, Lucy Taylor, and Mark Westcott. Using short podcasts to reinforce lectures. In UniServe Science Teaching and Learning Research Proceedings, pages 22-27, 2007.

[6] Palitha Edirsingha and Gilly K. Salmon. Pedagogical models for podcasts in higher education. In Proceedings of the EDEN Conference, 2007.

[7] Chris Evans. The effectiveness of m-learning in the form of podcast revision lectures in higher education. Computers \& Education, 50(2):491-498, February 2008.

[8] Maree Gosper, Margot McNeill, Karen Woo, Rob Phillips, Greg Preston, and David Green. Web-based lecture recording technologies: Do students learn from them? In Proceedings of EDUCAUSE Australasia 2007, 2007.

[9] C. McLoughlin and M. Lee. Listen and learn: A systematic review of the evidence that podcasting supports learning in higher education. In World Conference on Educational Multimedia, Hypermedia and Telecommunications, pages 1669-1677, 2007.

[10] Mark Prensky. Digital natives, digital immigrants. On the Horizon, 9:5, 2001.

[11] Chris Ribchester, Derek France, and Anne Wheeler. Podcasting: A tool for enhancing assessment feeedback. In 4th Conference on Education in a Changing Environment. Salford University, September 2007.

[12] S.K.A. Soong, L.K. Chan, C. Cheers, and C. Hu. Impact of video recorded lectures among students. In Australasian Society for Computers in Learning in Tertiary Education (ASCILITE) Conference 2006, 2006.

[13] Linda Thompson. Podcasting: The ultimate learning experience and authentic assessment. In ICT: Providing Choices for Learners and Learning. Proceedings of Asciilite Singapore 200\%, 2007. 